Acta Cryst. (1954). 7, 465

\title{
Long-Range-Short-Range Order in Calcic Plagioclases as a Continuous and Reversible Function of Temperature
}

\author{
By Fritz Laves* and Julian R. Goldsmith \\ Department of Geology, University of Chicago, Chicago 37, Illinois, U.S.A.
}

(Received 26 December 1953)

\begin{abstract}
A continuous structural change in anorthite $\left(\mathrm{CaAl}_{2} \mathrm{Si}_{2} \mathrm{O}_{8}\right)$ and contiguous plagioclases is described as a function of temperature and $\mathrm{NaAlSi}_{3} \mathrm{O}_{8}$ content. In pure anorthite, this transformation takes place over a temperature range of approximately $450^{\circ} \mathrm{C}$., and is complete or nearly complete at the melting point $\left(1554^{\circ} \mathrm{C}\right.$.). The presence of $\mathrm{NaAlSi}_{3} \mathrm{O}_{8}$ in solid solution greatly extends this temperature range. The transformation is manifested in single-crystal $\mathrm{X}$-ray photographs by the variation in diffuseness of certain $\mathrm{X}$-ray reflections, as a continuous and reversible function of temperature. To interpret the observations it is suggested that two structurally equivalent $\mathrm{Ca}(+\mathrm{Na})$ atom positions permit the development of out-of-step domains; the size (and shape) of these $\mathrm{Ca}(+\mathrm{Na})$ atom domains is an equilibrium function of temperature. The time required for the establishment of domain equilibrium varies with temperature, from a matter of minutes in the upper temperature range, to several days at approximately $800^{\circ} \mathrm{C}$. The transition is observable in plagioclase crystals of composition ranging from pure anorthite to approximately $27 \% \mathrm{NaAlSi}_{3} \mathrm{O}_{8}$.
\end{abstract}

\section{Introduction}

A new example of a continuous phase transition was described by the authors in a series of abstracts (Laves \& Goldsmith, 1951 $a, b, c$; Goldsmith \& Laves, 1951 ; see also Laves \& Goldsmith, 1954). This transition is observed in calcic plagioclases by the change in the diffuseness of certain $\mathrm{X}$-ray reflections as a function of temperature. The diffraction pattern was shown to consist of reflections subdivided in the following way: $\dagger$

(a) (hkl) with $l$ even and $(h+k)$ even.

(b) (hkl) with $l$ odd and $(h+k)$ odd.

(c) (hkl) with $(h+k+l)$ odd:

(1) $(h+k)$ even, $l$ odd;

(2) $(h+k)$ odd, $l$ even.

The type $(a)$, or 'main reflections', are characteristic of all feldspars; the $(b)$ reflections are dependent upon the $\mathrm{Al}-\mathrm{Si}$ distribution; the $(c)$ reflections are consequent upon the distribution of the calcium atoms. Additional evidence relating to these considerations will be presented at a later date.

Whereas the $(a)$ reflections are always found to be sharp, the $(b)$ and $(c)$ reflections may be sharp or diffuse. The $(c)$ reflections, in particular, show considerable variation in degree of diffuseness, both in natural calcic plagioclases and in synthetic anorthite, as a temperature-dependent function of heat treatment.

* Present address: Mineralogisch-petrographisches Institut der E.T.H., Zürich 6, Switzerland.

$\dagger$ Using the standard orientation of calcic plagioclases where $a \sim 8 \AA, b \sim 13 \AA, c \sim 2 \times 7 \AA, \alpha \sim 93^{\circ}, \beta \sim 116^{\circ}, \gamma \sim 91^{\circ}$. This cell contains $8 \mathrm{CaAl}_{2} \mathrm{Si}_{2} \mathrm{O}_{8}$ formula weights.

A C 7

\section{The effect of heat treatment on pure synthetic} anorthite

Small single crystals of pure synthetic anorthite were prepared from the melt, by the crystallization of less than 1 g. of glass. After crystallization near the melting point (pure anorthite melts at $1554^{\circ}$ C.) the small platinum crucible was removed from the furnace and cooled rapidly in air. Fig. 1 is an X-ray photograph of one of the crystals of pure synthetic anorthite; the different types of reflections are indicated. The single crystal of Fig. 1 was then subjected to the heat treatments shown in Table 1, X-ray photographs being taken after each heating. Fig. I corresponds to state (l) of Table 1.

Figs. 2-5 are $\mathrm{X}$-ray precession photographs of this same crystal taken after heat treatment at 1150,1300 , 1400 and $1500^{\circ}$ C.; the letter designation of each photograph corresponds to that of Table 1. The $\left(c_{1}\right)$ spots, being rather strong, are particularly useful for observing the effect of heat treatment. Four of these reflections are indicated in Fig. 2. All degrees of diffuseness can be produced in the $\left(c_{1}\right)$ spots, from sharp reflections at approximately $1100^{\circ} \mathrm{C}$., to those that virtually disappear at $1550^{\circ} \mathrm{C}$., just below the melting point.

It is quite apparent that an equilibrium is established in a rather short time, so that a particular 'degree of diffuseness' is produced in the $\left(c_{1}\right)$ spots characteristic of a particular temperature above $1150^{\circ} \mathrm{C}$. Table 1 also shows the reversibility of this process.

The 'degree of diffuseness' has been arbitrarily scaled between 0 and 10 on the basis of visual estimation. The $\left(c_{1}\right)$ reflections when completely sharp are designated as having zero 'degree of diffuseness'; the 


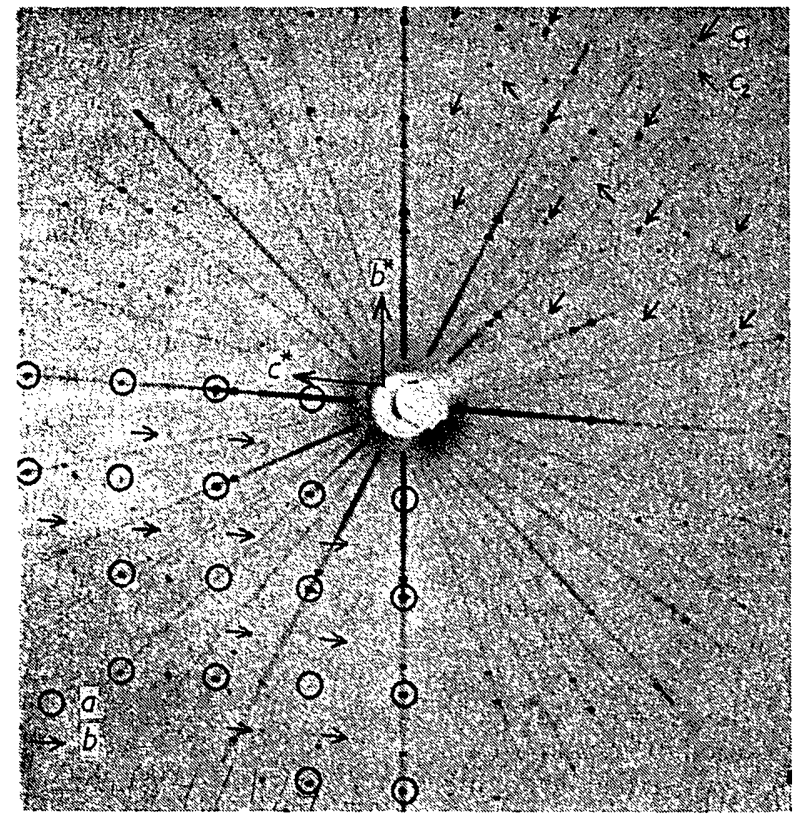

Fig. 1. Single-crystal $a$-axis precession picture of pure synthetic anorthite. The different types of reflections are indicated. Unfiltered $\mathrm{Cu}$ radiation used; $\beta$-reflections are unmarked, as are several additional spots due to contaminating Fe radiation.

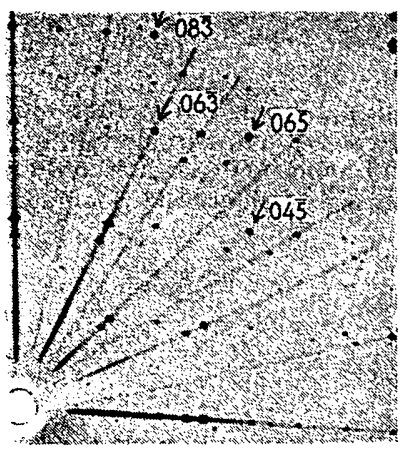

Fig. 2.

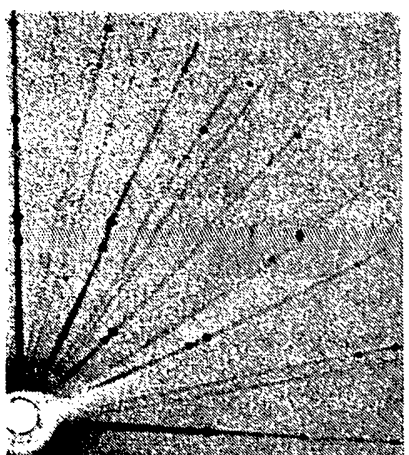

Fig. 4.

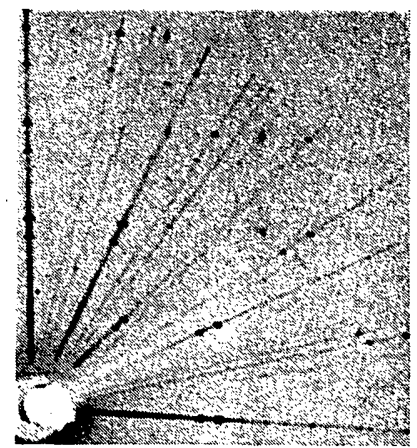

Fig. 3.

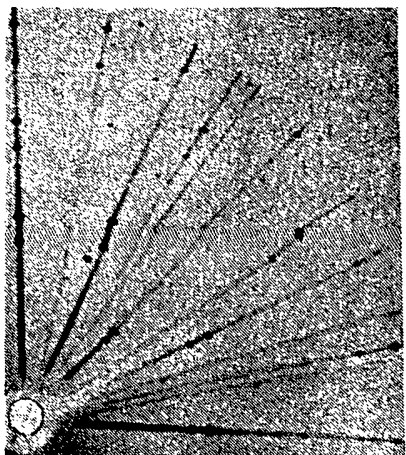

Fig. 5.

Figs. 2-5. Portions of single-crystal $a$-axis precession pictures of pure synthetic anorthite. Fig. 2 taken after heat treatment at $1150^{\circ}$ C. Fig. 3 at $1300^{\circ}$ C., Fig. 4 at $1400^{\circ}$ C., and Fig. 5 at $1500^{\circ}$ C. Four of the stronger $\left(c_{1}\right)$ reflections are indicated (with indices) in Fig 2. Unfiltered Cu radiation, $45 \mathrm{kV}$., $15 \mathrm{~mA}$., exposure $\sim 12 \mathrm{hr}$. The 'degrees of diffuseness' are respectively $0 \cdot 2,2-3,6$, and 9. 
Table 1. Thermal and X-ray data on pure synthetic anorthite*

$\begin{array}{cc}\text { Experiment } & \text { Temperature }\left({ }^{\circ} \mathrm{C} .\right) \\ a & \text { As crystallized } \\ b & 1400 \\ c & 1400 \\ d & 1300 \\ e & 1150 \\ f & 1500 \\ g & 1500 \\ h & 1150 \\ i & 1150 \\ j & 1300 \\ k & 1300 \\ l & 1300 \\ m & 1400 \\ n & 1400\end{array}$

\begin{tabular}{cl} 
Time (hr.) & \multicolumn{1}{c}{ Condition of $(c)$ reflections } \\
\hline & Very diffuse \\
48 & Quite diffuse \\
96 & Quite diffuse \\
48 & Slightly diffuse \\
96 & Virtually sharp \\
$0 \cdot 25$ & Very diffuse \\
6 & Very diffuse \\
1 & Virtually sharp \\
168 & Virtually sharp \\
1 & (Sample water-quenched) slightly diffuse \\
1 & (Sample cooled in $\sim 15$ sec.) no change \\
1 & (Sample water-quenched) no change \\
1 & (Sample water-quenched) quite diffuse \\
1 & (Sample cooled in $\sim 15$ sec.) no change \\
Same crystal used in all above experiments.
\end{tabular}

Degree of diffuseness of $\left(c_{1}\right)$ reflections

8
6
6
2
$0 \cdot 2$
9
9
$0 \cdot 2$
$0 \cdot 2$
$2-3$
$2-3$
$2-3$
6
6

value of 10 is assigned to $\left(c_{1}\right)$ reflections that disappear by spreading into the background, even in heavily exposed X-ray photographs. On this basis, Figs. 2-5 represent degrees of diffuseness as shown:

$\begin{array}{llccc}\text { Fig. } & 2 & 3 & 4 & 5 \\ \text { Diffuseness } & 0.2 & 2-3 & 6 & 9\end{array}$

This measure of diffuseness is, of course, qualitative, and certainly not accurate to more than approximately $\pm \frac{1}{2}$ of a unit.

The above heat treatments and $\mathrm{X}$-ray photographs were all made with the same crystal (approximately $0.3 \mathrm{~mm}$. in size). The same procedure was used in the work done on different specimens, to be described. The crystals were contained in tiny envelopes of platinum foil and heated in a platinum-wound quenching furnace. To determine what constitutes a 'quench', several cooling rates were tried. As indicated in Table 1, even moderately slow removal from the furnace into air is sufficiently fast; see runs $(j) v .(k)$ and $(m)$ $v$. $(n)$. Runs $(k)$ and $(n)$ were withdrawn from the furnace rather slowly (samples pulled through the temperature gradient and into air in a period of approximately $15 \mathrm{sec}$.). This treatment produced results that could not be distinguished from an instantaneous water quench. All other runs on these and other samples were therefore quenched by rapid removal into the air and by immediately blowing the breath on the envelope.

It is clear that the degree of diffuseness of the (c) reflections is a reversible function of the temperature, and equilibrium is attainable from either direction in a short time.

\section{Structural interpretation of the diffuseness}

Publication of the full body of the writers' data on the plagioclases has been delayed in order to obtain more detailed information on the nature of the diffuse reflections in reciprocal space as a function of temperature, but certain information pertinent to the problem will be pointed out here. The fact that the $(a)$ reflections are sharp and unchanged at all temperatures up to the melting point indicates that a fundamental framework is maintained over the whole temperature range. Investigation of the reflection intensities produced by gallium- and germanium-containing synthetic anorthites as compared with normal (Al-Si) anorthite (Goldsmith \& Laves, 195l) led the writers to the conclusion that the $(b)$ reflections were a consequence of an ordered $\mathrm{Al}-\mathrm{Si}$ distribution. This was also independently concluded by Sörum $(1951,1953)$ through the determination of the structure of a plagioclase (approximately $70 \% \mathrm{An}$ ).

The conclusion that the $(c)$ reflections depend on the distribution of Ca atoms was drawn from two lines of evidence. First, the rapid equilibrium, obviously a low-energy phenomenon, cannot be ascribed to a rearrangement of the $\mathrm{Al}-\mathrm{Si}-\mathrm{O}$ framework. The extreme sluggishness of structural changes dependent upon Si-Al exchange has been discussed by Goldsmith (1952), Laves $(1952 a, b)$, and Goldsmith \& Laves (1954). The second, and more direct line of evidence was afforded by a study of the gallium- and germaniumcontaining anorthites mentioned above.

Diffuse reflections associated with sharp reflections from the same crystal have been investigated by a number of workers (see, for example, Lipson, 1950). In all cases, this phenomenon is consequent upon disorder associated with some type of short-range order. If one interprets the critical temperature of disorder $\left(T_{c}\right)$ as that temperature above which no long-range order is present, observations reported in the literature can be divided in two categories. Cowley $(1950 a, b)$ was able to show a temperature denciidency of the size and shape of diffuse reflcuilons above $T_{c}$ in the alloy $\mathrm{Cu}_{3} \mathrm{Au}$. At temperatures below $T_{c}$, several attempts have been made to correlate diffuse reflections in alloys with the size and shape of 'domains' within the crystal (see treatment and further references in Edmunds \& Hinde, 1952). No data are reported, however, indicating whether or not there is an equilibrium development of domains with temperature below $T_{c}$; that is, whether or not any particular feature 


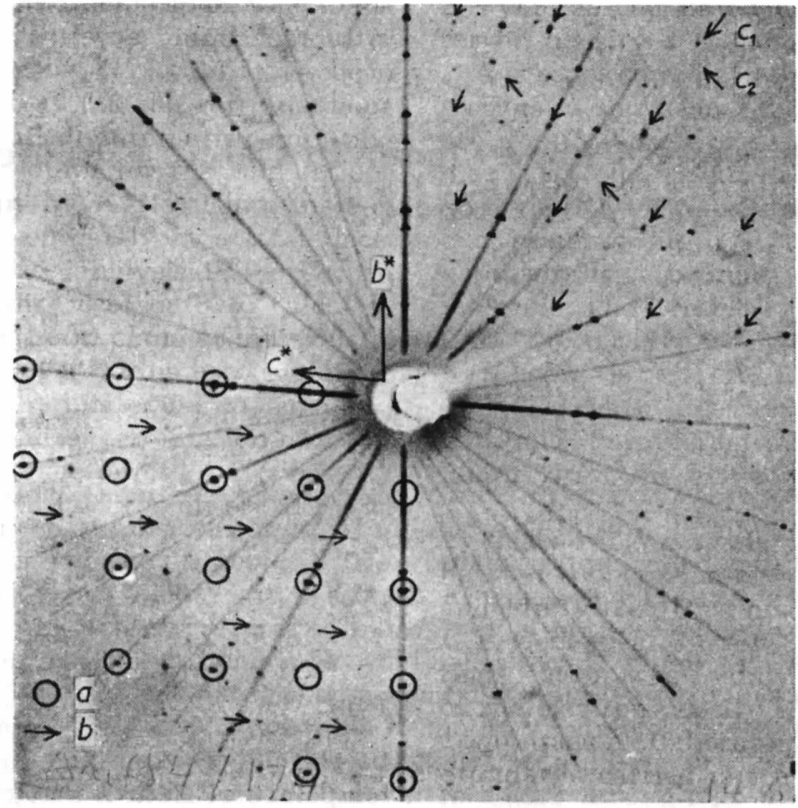

Fig. 1. Single-crystal $a$-axis precession picture of pure synthetic anorthite. The different types of reflections are indicated. Unfiltered $\mathrm{Cu}$ radiation used; $\beta$-reflections are unmarked, as are several additional spots due to contaminating Fe radiation.

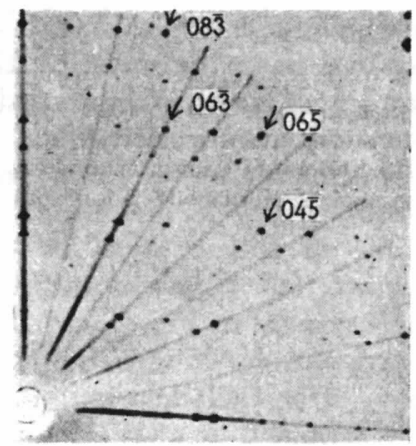

Fig. 2.

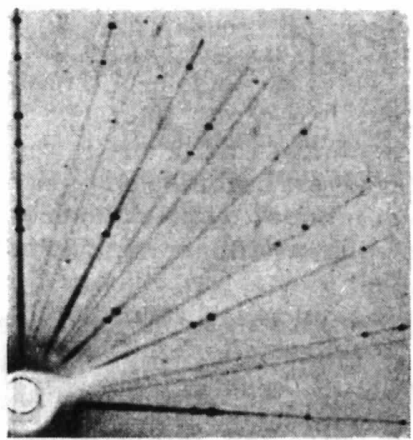

Fig. 4.

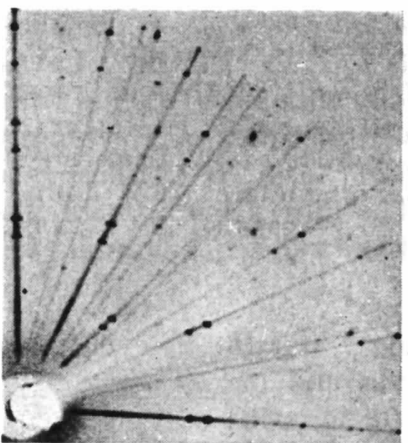

Fig. 3.

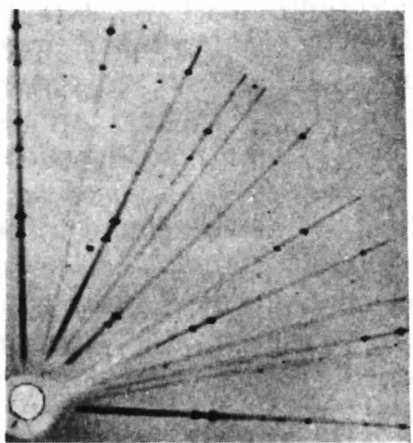

Fig. 5.

Figs. 2-5. Portions of single-crystal $a$-axis precession pictures of pure synthetic anorthite. Fig. 2 taken after heat treatment at $1150^{\circ}$ C. Fig. 3 at $1300^{\circ}$ C., Fig. 4 at $1400^{\circ}$ C., and Fig. 5 at $1500^{\circ}$ C. Four of the stronger $\left(c_{1}\right)$ reflections are indicated (with indices) in Fig 2 . Unfiltered Cu radiation, $45 \mathrm{kV}$., $15 \mathrm{~mA}$., exposure $\sim 12 \mathrm{hr}$. The 'degrees of diffuseness' are respectively $0 \cdot 2,2-3,6$, and 9 . 
of the diffuse reflections can be identified as an equilibrium property of some particular temperature.

It was shown that the diffuseness of the $(c)$ reflections in anorthite is a continuous and reversible function of temperature in the range from $1100^{\circ} \mathrm{C}$. to the melting point. No discontinuity was observed. No analogous example is known to the writers. The X-ray effects appear to be best explained qualitatively by the following assumptions :

(1) There are two equivalent sets of lattice complexes that can be occupied by calcium ions; either arrangement produces an identical anorthite structure. These two sets can be called $A$ and $B$.

(2) If all the calcium ions in an anorthite crystal were contained in either the $A$-sites or the $B$-sites, it would be fully ordered with respect to calcium, and the diffraction pattern would show sharp $(c)$ reflections.

(3) If the calcium ions are distributed completely at random in the $A$-sites and the $B$-sites, the crystal is perfectly disordered with respect to calcium, and the $(c)$ reflections would vanish into the background.

(4) If there are volumes within the crystal in which $A$-sites on the one hand, and $B$-sites on the other hand predominate, ${ }^{*}$ these volumes can be called domains.

(5) The size and shape of such out-of-step domains will influence the intensity distribution of the (c) reflections. Qualitatively, the smaller the domains the more diffuse the reflections.

(6) The observations on the temperature dependency of the $(c)$ reflections indicate that the domain size is a function of temperature, continuously ranging from exceedingly small domains at just below the melting point, to large domains that are effectively single

* Predominate in the sense that a greater number of $A$ or $B$ sites are occupied within a volume than would be by the development of local predominance expected within any small volume on the basis of statistical fluctuations. crystals (in terms of $\mathrm{X}$-ray diffraction) at approximately $1100^{\circ} \mathrm{C}$. in the case of pure anorthite.

(7) It is probable that the domain shapes are highly complex, and might not consist of finite volumes that are topologically equivalent to convex bodies. They might be as complex as two intertwined irregular networks. In this case, the 'domain size' might be represented by the two-dimensional area of a domain as revealed in a cross-section; or more properly, by the integrated 'interfacial' area dividing the $A$ and $B$ domains.

(8) The energy required to shift an individual calcium atom from an $A$-site to a $B$-site is very small, and as a consequence, the shifting of 'interfacial' areas involved in a change of domain size does not demand large energies. These energies are probably of the same order of magnitude as those necessary to move dislocations and shift twin boundaries in many substances.

\section{Investigation of natural calcic plagioclases}

In addition to the work on pure synthetic anorthite, twenty other crystals were examined. These specimens were from nine different occurrences, including one meteorite. All of these crystals were subjected to the same type of heat treatment as described in the case of synthetic anorthite. One of the samples was a single crystal produced in the laboratory from a melt of natural anorthite from Maikejima, Japan. All other specimens were fragments taken from larger natural crystals. Table 2 lists the crystals used, with composition indicated. (The compositions quoted were determined on the same tiny crystal fragment used for the thermal and $\mathrm{X}$-ray work, or on an immediately adjacent fragment which was melted to a glass and a determination made based on the refractive index of the glass (see Foster, 1952).)

Tables 3-11 contain the thermal and X-ray data on the natural materials, presented in the same fashion

Table 2. Specimens examined

Specimen No.
1
2
3
4
5
6
7
8
9
10
11
12
13
14
15
16
17
18
19
20

\section{Locality}

Synthetic

Corundum anorthosite, Salem, India

Corundum anorthosite, Salem, India

Corundum anorthosite, Salem, India

Crystals in marble, Pasmeda, Tyrol

Eucrite, Wadaki, Japan

Eucrite, Wadaki, Japan

Granulite facies rock, W. Greenland

Crystal lapilli, Miakejima, Japan

Crystal lapilli, Miakejima, Japan

Crystal lapilli, Miakejima, Japan

Crystallized from melt of Miakejima material

Plagioclase-pyroxene rock, G rass Valley, Calif.

Plagioclase-pyroxene rock, Grass Valley, Calif.

Plagioclase-pyroxene rock, Grass Valley, Calif.

Achondritic meteorite (Juvinas)

Troctolite, Merrill, Wisc. (Emmons, No. 166)

Anorthosite, India

Anorthosite, Split Rock Pt., Minn. (Emmons, No. 1A)

Anorthosite, Split Rock Pt., Minn. (Emmons, No. 1B)
Anorthite content (Mol. \%)

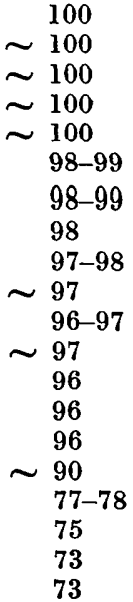


as for the synthetic anorthite of Table 1. Discussion of the data follows.

\section{Diffuseness of the $\left(c_{1}\right)$ reflections as a continuous function} of temperature

The reversibility and reproducibility with temperature of the degree of diffuseness of the $\left(c_{1}\right)$ reflections

$\begin{array}{ccl}\begin{array}{c}\text { Table 3. Anorthite, Salem, India, } \sim 100 \% \text { An* } \\ \begin{array}{c}\text { Specimen } \\ \text { No. }\end{array}\end{array} & \begin{array}{c}\text { Heat treatment } \\ \left({ }^{\circ} \mathrm{C} .\right)\end{array} & \begin{array}{c}\text { Degree of diffuseness } \\ \text { of }\left(c_{1}\right) \text { reflections }\end{array} \\ 2 & \text { None } & 0 \text { (sharp) } \\ 2 & 1150,168 \mathrm{hr} . & 0.5 \text { (virtually sharp) } \\ 3 & \text { None } & 0 \\ 3 & 1548, \frac{1}{2} \mathrm{hr} . & 10 \\ 4 & \text { None } & 0 \\ 4 & 1534, \frac{1}{2} \mathrm{hr} . & 9-10 \\ 4 & 1000,64 \mathrm{hr} . & 0\end{array}$

* Determined by chemical analysis, spectrographic analysis, and melting point.

\section{Table 4. Anorthite, Pasmeda, Tyrol, $100 \%$ An*}

$\begin{array}{ccc}\begin{array}{c}\text { Specimen } \\ \text { No. }\end{array} & \begin{array}{c}\text { Heat treatment } \\ \left({ }^{\circ} \mathrm{C} .\right)\end{array} & \begin{array}{c}\text { Degree of diffuseness } \\ \text { of }\left(c_{1}\right) \text { reflections }\end{array} \\ \mathbf{5} & \text { None } & 0 \text { (sharp) } \\ \mathbf{5} & 1150,3 \mathrm{hr} . & 0 \\ \mathbf{5} & 1400,1 \mathrm{hr} . & 6 \\ 5 & 1150,3 \mathrm{hr} . & 0\end{array}$

\section{Table 5. Anorthite, Wadaki, Japan, 98-99\% An*}

$\begin{array}{cll}\begin{array}{c}\text { Specimen } \\ \text { No. }\end{array} & \begin{array}{c}\text { Heat treatment } \\ \left({ }^{\circ} \mathrm{C} .\right)\end{array} & \begin{array}{c}\text { Degree of diffuseness } \\ \text { of }\left(c_{1}\right) \text { reflections }\end{array} \\ 6 & \text { None } & 0 \text { (sharp) } \\ 6 & 1507,5 \frac{1}{2} \mathrm{hr} . & 9-10 \\ 6 & 1150,168 \mathrm{hr} . & 2 \\ 7 & \text { None } & 0.5 \text { (virtually sharp) } \\ 7 & 1150,168 \mathrm{hr} . & 2 \\ 7 & 1000,64 \mathrm{hr} . & 1 \\ 7 & 900,168 \mathrm{hr} . & 0.5\end{array}$

* Determined by refractive index of glass produced by melting fragment of the crystal.

Table 6. Anorthite, Greenland, $98 \%$ An*

$\begin{array}{ccl}\begin{array}{c}\text { Specimen } \\ \text { No. }\end{array} & \begin{array}{c}\text { Heat treatment } \\ \left({ }^{\circ} \mathrm{C} .\right)\end{array} & \begin{array}{c}\text { Degree of diffuseness } \\ \text { of }\left(c_{1}\right) \text { reflections }\end{array} \\ 8 & \text { None } & 0 \text { (sharp) } \\ 8 & 1000,24 \mathrm{hr} . & 0 \\ 8 & 1100,24 \mathrm{hr} . & 0 \cdot 2 \text { (virtually sharp) } \\ 8 & 1200,24 \mathrm{hr} . & 2 \\ 8 & 1300,24 \mathrm{hr} . & 5 \\ 8 & 1400,24 \mathrm{hr} . & 7 \\ 8 & 1500,3 \mathrm{hr} . & 9 \\ 8 & 1150,1 \mathrm{hr} . & 2\end{array}$

* Determined by refractive index of glass produced by melting fragment of the crystal.
Table 7. Anorthite, Miakejima, Japan, 97\% An (variable)*

$\begin{array}{clc}\begin{array}{c}\text { Specimen } \\ \text { No. }\end{array} & \begin{array}{c}\text { Heat treatment } \\ \left({ }^{\circ} \mathrm{C} .\right)\end{array} & \begin{array}{c}\text { Degree of diffuseness } \\ \text { of }\left(c_{1}\right) \text { reflections }\end{array} \\ 9 & \text { None } & 5 \\ 9 & 1150,1 \mathrm{hr} . & 5-6 \\ 9 & 1150,72 \mathrm{hr} . & 5-6 \\ 9 & 1500,3 \mathrm{hr} . & 9 \\ 9 & 1150,72 \mathrm{hr} . & 5-6 \\ 9 & 1000,24 \mathrm{hr} . & 4-5 \\ 9 & 1150,24 \mathrm{hr} . & 5-6 \\ 9 & 900,168 \mathrm{hr} . & 3-4 \\ & & \\ 10 & 1540, \frac{1}{2} \mathrm{hr} . & 5 \\ 10 & 1150,168 \mathrm{hr} . & 5 \\ & & 8 \\ 11 & \text { None } & 9 \\ 11 & 1400,6 \mathrm{hr} . & 9 \\ 11 & 1510,6 \mathrm{hr} . & 3 \\ 11 & 1510,96 \mathrm{hr} . & 9\end{array}$

* Specimen No. $9=97-98 \%$ An, determined by refractive index of glass produced by melting fragment of the crystal.

Specimen No. 10, composition undetermined.

Specimen No. 11, 96-97\% An, determined from refractive index of its glass.

Table 8. Recrystallized anorthite, from melt of material from Miakejima, Japan, 97\% An*

\begin{tabular}{|c|c|c|}
\hline $\begin{array}{l}\text { Specimen } \\
\text { No. }\end{array}$ & $\begin{array}{l}\text { Heat treatment } \\
\left({ }^{\circ} \mathrm{C} .\right)\end{array}$ & $\begin{array}{l}\text { Degree of diffuseness } \\
\text { of }\left(c_{1}\right) \text { reflections }\end{array}$ \\
\hline 12 & $a$. Original, as crystallized & $\begin{array}{ll}d & 7\end{array}$ \\
\hline 12 & b. $1530,5 \mathrm{hr}$. & 10 \\
\hline 12 & c. $1400,6 \mathrm{hr}$. & 8 \\
\hline 12 & d. $1400,21 \mathrm{hr}$. & 8 \\
\hline 12 & e. $1530,5 \frac{1}{2} \mathrm{hr} . \dagger$ & 10 \\
\hline 12 & f. $1400,5 \frac{1}{2} \mathrm{hr}$. & 8 \\
\hline 12 & g. $1400,48 \mathrm{hr}$. & 8 \\
\hline 12 & h. $1300,48 \mathrm{hr}$. & 6 \\
\hline 12 & i. $1150,48 \mathrm{hr}$. & 3 \\
\hline 12 & j. $1150,96 \mathrm{hr}$. & 3 \\
\hline 12 & $k .1500,0.2 \mathrm{hr}$. & 10 \\
\hline 12 & l. $1500,6 \mathrm{hr}$. & 10 \\
\hline 12 & $m .1530,0.25 \mathrm{hr}$. & 10 \\
\hline 12 & $n .1530,6 \mathrm{hr}$ & 10 \\
\hline 12 & o. $1150,170 \mathrm{hr}$. & 3 \\
\hline 12 & p. $850,170 \mathrm{hr}$. & 1 \\
\hline 12 & $q .1150,24 \mathrm{hr}$. & 3 \\
\hline
\end{tabular}

* Composition not determined directly, but material used for crystallization was $97 \%$ An.

$\dagger$ Slight melting noted in surface of crystal.

Table 9. Anorthite, Grass Valley, California, 96\% An*

$\begin{array}{clc}\begin{array}{c}\text { Specimen } \\ \text { No. }\end{array} & \begin{array}{c}\text { Heat treatment } \\ \left({ }^{\circ} \mathrm{C} .\right)\end{array} & \begin{array}{c}\text { Degree of diffuseness } \\ \text { of }\left(c_{1}\right)\end{array} \\ 13 & \text { None } & 1 \\ 13 & 1430,1 \frac{1}{2} \mathrm{hr} . & 8-9 \\ 13 & 1150,24 \mathrm{hr} . & 6 \\ 13 & 1000,64 \mathrm{hr} . & 5 \\ & & \\ 14 & \text { None } & 1 \\ 14 & 1150,24 \mathrm{hr} . & 4 \\ 14 & 900,168 \mathrm{hr} . & 3 \\ 14 & 750,114 \mathrm{hr} . & \\ 15 & & 1 \\ 15 & \text { None } & 2\end{array}$

* Determined by refractive indices, and index of glass melted from fragment of crystal. 
Table 10. Anorthite from meteorite, Juvinas, 90\% An*

$\begin{array}{ccc}\begin{array}{c}\text { Specimen } \\ \text { No. }\end{array} & \begin{array}{c}\text { Heat treatment } \\ \left({ }^{\circ} \mathrm{C} .\right)\end{array} & \begin{array}{c}\text { Degree of diffuseness } \\ \text { of }\left(c_{1}\right) \text { reflections }\end{array} \\ 16 & \text { None } & 4-5 \\ 16 & 1150,168 \mathrm{hr} . & 8 \\ 16 & 1000,64 \mathrm{hr} . & 6-7 \\ 16 & 900,168 \mathrm{hr} . & 6-7\end{array}$
Table 11. Data on plagioclases in composition range
$70-80 \%$ An

$\begin{array}{cc}\begin{array}{c}\text { Specimen } \\ \text { No. }\end{array} & \text { Mol. \% An* } \\ 17 & 77-78\end{array}$

\section{X-ray observations}

$\left(c_{1}\right)$ reflections very diffuse; degree of diffuseness near 10. (b) reflections sharp. $\left(c_{1}\right)$ reflections still observable after $5 \mathrm{hr}$, at $1150^{\circ} \mathrm{C}$.

$\left(c_{1}\right)$ reflections considerably sharper than above; degree of diffuseness $\sim 7$. (b) reflections are split $\left(\delta_{c}=\right.$ $\left.167^{\circ}\right), \dagger$ but connected by diffuse lines $\sim \perp(01 \overline{1})$; true cell

$\left(c_{1}\right)$ reflections exceedingly diffuse, barely observable. In $60 \mathrm{hr}$. $e x$ posures, reflections become apparent. (b) reflections sharp

$\left(c_{1}\right)$ reflections not observed, even after $60 \mathrm{hr}$. exposure. (b) reflections sharp

* Composition determined by refractive indices on (010) or (001) cleavage. Specimens 17, 19 and 20 described by Emmons (1953). Chemical analyses listed by Emmons in weight \% show specimen 17 (Emmons, No. 166) to be $81.5 \%$ An, specimen 19 (Emmons, No. $1 A$ ) is $77 \cdot 2 \%$ An, and specimen 20 (Emmons, No. $1 B$ ) is $76.8 \%$ An. Specimens 17, 19, and 20 come from the same samples from which Cole et.al. (1951) took their samples Nos. 25, 1, and 2. Our determinations show 2-3\% less An than Emmon's, even after converting his data to mol. \%. One must consider compositional variations within a sample, however, and must determine the composition of the particular tiny crystal used. This point is also mentioned by Cole et al. (1951).

$\dagger$ Notation of Cole et al. (1951). This value of $167^{\circ}$ is larger than any observed by Cole et al., but is present in a more calcic plagioclase than they had found to contain split (b) reflections. The value fits their extrapolated curve (Fig. 2, p. 26) exceedingly well, i.e. $\delta_{c}=167^{\circ}$ should be found in plagioclase of $75 \%$ An. Another observation should be mentioned. Many of the main reflections show satellite reflections, an observation also noted briefly by the above authors. In this material, these satellites have an average intensity approximately 10 times that of the $(b)$ reflections (and are also connected to the main reflections by diffuse streaks), those observed by Cole et al. were reported to have intensities 100 times less than the $(b)$ reflections. The satellites here noted, along with the split $(b)$ reflections, can be indexed on the basis of a superstructure $\sim 200 \AA$ in the $c$ direction. These reflections appear in $c$-axis rotation photographs on the $2 \mathrm{nd}, 26 \mathrm{th}$, 30th, 54th, and 58th layer lines (the main reflections appear on the 0th, 28th, and 56th layer lines); the (b) reflections appear on the 13th, 15th, 41st, 43rd, 69th, and 7 lst layer lines.

was observed in all of the specimens studied. As in the case of pure anorthite, a specific degree of diffuseness is characteristic of a particular temperature, although variable between specimens. This is clearly shown in the tabulated data. For example, specimen No. 12 (Table 8) was subjected to a series of 16 heat treatments at temperatures of $850,1150,1300,1400,1500$, and $1530^{\circ} \mathrm{C}$., and a specific diffuseness was observed in the $\left(c_{1}\right)$ reflections for each temperature, irrespective of the previous heat treatment. The diffuseness value was 3 at $1150^{\circ} \mathrm{C}$., whether approached from temperatures above $1150^{\circ}, \mathrm{C}$., as in states $(i)$ and $(o)$, or from below $1150^{\circ} \mathrm{C}$., as in state $(q)$. In Table 5 , it is seen that the diffuseness value of 2 is characteristic of the Wadaki anorthite at $1150^{\circ} \mathrm{C}$., whether produced from the originally sharp state, as in sample No. 7, or from the very diffuse state first produced by heating at $1507^{\circ} \mathrm{C}$., as in sample No.6. As shown in the remaining tables, all of the specimens examined from this point of view exhibit this reversible behavior. It is quite clear that an equilibrium relating temperature and the degree of diffuseness of the $\left(c_{1}\right)$ reflections is established in natural calcic plagioclases as it was in the case of pure synthetic anorthite. The specific values of diffuseness as a function of temperature are discussed below with relation to the sodium content of the samples. In addition, the continuous nature of this transition is illustrated in a plot of the data of Tables 1, 6, 7, 9 and 10, shown as Fig. 6 .

\section{Diffuseness of the $\left(c_{1}\right)$ reflections as a function of $\mathrm{NaAlSi}_{3} \mathrm{O}_{8}$ content}

In pure synthetic anorthite observable diffuseness of the $\left(c_{1}\right)$ reflections does not set in until a temperature of approximately $1100-1150^{\circ} \mathrm{C}$. is reached.* Tables 3 and 4 show that the same is true of pure or virtually pure natural anorthites. The effect of $\mathrm{NaAlSi}_{3} \mathrm{O}_{8}$ content on the relation between temperature and $\left(c_{1}\right)$ reflection diffuseness is, however, quite striking. Fig. 6 illustrates this effect by data on six of the crystals. At $1150^{\circ}$ C., equilibrium degrees of diffuseness of $0,2,3,5-6,6$, and 8 are shown for these six samples. Thus a change from $100 \%$ to approximately $90 \%$ An produces a spread over the greater part of the diffuseness range at this temperature. The change produced by even a few per cent $\mathrm{NaAlSi}_{3} \mathrm{O}_{8}$ is very great indeed.

The general trend of the curves suggests that they reach a value of 10 (virtual disappearance of the $\left(c_{1}\right)$ reflections) at or near the melting points of the respective specimens. Fig. 6 also suggests that plagioclase compositions, somewhat more sodic than $90 \%$ An, might have $\left(c_{1}\right)$ reflections so diffuse, even at low temperatures, that these reflections might escape observation. $t$

It can also be seen from Fig. 6 that although pure anorthite develops sharp $\left(c_{1}\right)$ reflections below $1150^{\circ} \mathrm{C}$.,

* In this and succeeding discussions of temperature, reference is to the high-temperature equilibrium state as observed in quenched crystals.

$\dagger$ The effect of the sodium content on the diffuseness of the 


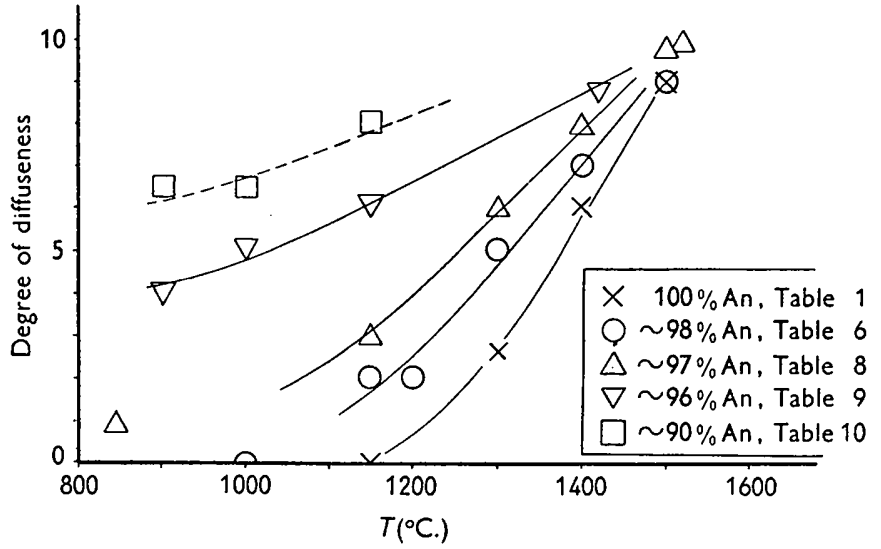

Fig. 6. Plot of 'degree of diffuseness' of the $\left(c_{1}\right)$ reflections $v$. temperature for six calcic plagioclases in the composition range $\sim 90-100 \%$ anorthite.

the presence of only moderate amounts of $\mathrm{NaAlSi}_{3} \mathrm{O}_{8}$ very markedly lowers the maximum temperature consistent with sharp reflections. For example, a crude (and admittedly uncertain) extrapolation of the diffuseness-temperature curve of the Grass Valley anorthite would indicate that sharp $\left(c_{1}\right)$ spots could only be developed below roughly $400^{\circ} \mathrm{C}$. Thus plagioclases containing somewhat more than approximately $5 \% \mathrm{NaAlSi}_{3} \mathrm{O}_{8}$ might be expected to show $\left(c_{1}\right)$ reflections that cannot be made sharp in any reasonable length of time, owing to the low rate of ionic movement at these low temperatures. Furthermore, it is not unlikely that plagioclases with approximately $10 \%$ or more $\mathrm{NaAlSi}_{3} \mathrm{O}_{8}$ cannot show sharp $\left(c_{1}\right)$ reflections at all, as the 'sharpening temperature' may lie below normal earth-surface temperatures.

It is not certain that this effect on the temperaturediffuseness relation can be solely attributed to $\mathrm{NaAlSi}_{3} \mathrm{O}_{8}$ content. It is apparent that the $\left(c_{1}\right)$ reflections are controlled by the $\mathrm{Ca}(+\mathrm{Na})$ atom distribution. The $\mathrm{Na}$ atoms may well act as any other impurity and thus strongly influence the domain-temperature relations. On the other hand, as $\mathrm{Na}$ enters the structures, the $\mathrm{Al}: \mathrm{Si}$ ratio of the fundamental framework is also changed. The secondary effect of the change in the framework on the Ca-atom domains is not known.

\section{Additional data on isomorphism in the range $70 \%-100 \%$ anorthite}

Cole, Sörum \& Taylor (1951) report that in a plagioclase with $72 \% \mathrm{An}$, the reflections that are here called

(c) reflections is also discussed by Gay \& Taylor (1953) and by Gay (1953). Their observations, however, were limited to specimens that were not heat treated, and therefore conclusions could not be drawn as to the equilibrium states. The vory diffuse nature of $(c)$ reflections in plagioclases more sodic than $\sim 90 \%$ An can account for the fact that Gay (1953) reported them absent in plagioclases with $20 \%$ or more $\mathrm{NaAlSi}_{3} \mathrm{O}_{8}$. These reflections have been observed by the present writers in compositions up to $\sim 27 \% \mathrm{NaAlSi}_{3} \mathrm{O}_{8}$, as will be discussed shortly. the $(c)$ reflections are absent. They state, 'We do not know whether the change from the body-centred to the primitive anorthite structure takes place discontinuously or by the gradual appearance of the additional reflections on passing from 72 to $100 \%$ anorthite'. The above authors thus have no evidence to show that the $(c)$ reflections (indicative of a primitive cell) disappear at any particular composition between $100 \%$ and $72 \%$ An. Cole et al. propose two alternative models to explain their findings; the first proposal is that 'The region $100-85 \%$ anorthite is then one of true isomorphous substitution, in which random replacement of calcium and aluminium by sodium and silicon atoms raises the true symmetry from primitive to body-centered'. Their second alternative is, '... the whole range $100-72 \%$ anorthite corresponds to isomorphous substitution, with the associated symmetry change'. The first model is based on the extrapolation of a relationship between composition and the amount of 'splitting' of certain superstructure reflections (here called $(b)$ reflections). No data are presented to support the second model. In the light of the data here presented it is now apparent that the change from the primitive anorthite structure to the body-centered structure is a gradual one. This view was independently arrived at by Gay (1953). However, it should be noted that this change is manifested by the gradual diffusing into the background of the (c) reflections, and not by the gradual diminution in total intensity of the reflections.

Specimens 17-20 (Table 2) were examined for the purpose of extending the composition limits to the point where the $(c)$ reflections might not be observable. Table 11 presents the data on these crystals. Sample 19 shows that $\left(c_{1}\right)$ reflections, although exceedingly diffuse, can be present in a plagioclase of $73 \%$ An. This indicates that the first of the two alternative models proposed by Cole et al. can be discarded, and that the gradual change in the structure extends at least to $73 \%$ An. On the other hand, it should be noted that specimen 18 (75\% An, Table 11) has (b) 
reflections that are split, which is unexpected in the light of the data of Cole et al., who state that the splitting was not observed in plagioclases more calcic than $71.5 \%$ An. The following tentative suggestions are made:

(1) The $(b)$ and $(c)$ reflections are not directly related to each other; the splitting of the $(b)$ reflections, and the presence and degree of diffuseness of the $(c)$ reflections are not completely interdependent. This is likely in the light of the order-disorder relations mentioned in the introductory statements.

(2) Variations in the correlation between $(b)$ and $(c)$ reflections might be a function of the thermal history of the specimen. The $(c)$ reflections can be relatively easily changed, whereas the $(b)$ reflections cannot, inasmuch as they are controlled by the strongly bonded $\mathrm{Al}$ and $\mathrm{Si}$ atoms.

(3) It is thus possible that the 'first model' proposed by Cole et al. is correct for low-temperature plagioclases in the range considered (70-100\% An).

(4) This model, however, is incorrect for what may be considered high temperature plagioclases, as it is here shown that the structural change is continuous between approximately $70 \%$ and $100 \%$ An.

\section{Time required for equilibration}

Several experiments were carried out to obtain some information on the rate at which equilibrium is established. For example, Tables 1 and 7 show that times of $15 \mathrm{~min}$. and $\frac{1}{2} \mathrm{hr}$. were sufficient for equilibrium at temperatures of $1500-1540^{\circ} \mathrm{C}$.; it is quite probable that several minutes would have been ample. At $1150^{\circ} \mathrm{C}$., $1 \mathrm{hr}$. was found to be sufficient, as evidenced from Tables 1 and 6 . No experiments of shorter duration were carried out. Experiments at $900^{\circ} \mathrm{C}$. were done on a crystal of the Salem, India, anorthite (data not included in Table 3). This crystal, originally with sharp $\left(c_{1}\right)$ reflections, was heated $30 \mathrm{~min}$. at $1530^{\circ} \mathrm{C}$., producing a diffuseness value of $9-10$. It was then held $1 \mathrm{hr}$. at $900^{\circ} \mathrm{C}$. Sharp $\left(c_{1}\right)$ reflections appeared, although a diffuse area remained around the sharp spots. It can be concluded that equilibrium was not quite reached in $1 \mathrm{hr}$., and that some of the residual short-range order was superimposed on the long-range order (stable in this material below approximately $1150^{\circ} \mathrm{C}$.). An additional heating period of $24 \mathrm{hr}$. at $900^{\circ} \mathrm{C}$. obliterated the weak diffuseness; equilibrium is thus established in a period of less than $24 \mathrm{hr}$. at $900^{\circ} \mathrm{C}$, and probably in several hours. Equilibrium was attempted at only one temperature below $900^{\circ} \mathrm{C}$. Two crystals of the Grass Valley anorthite (Table 9) were held for $114 \mathrm{hr}$. at $750^{\circ} \mathrm{C}$. One (specimen 15) had not previously been heated and showed a diffuseness value of 1 . The other (specimen 14) had previously been equilibrated at $900^{\circ} \mathrm{C}$., with a diffuseness value of 4 . Specimen 14 developed a diffuseness value of 3 during this treatment, whereas specimen 15 was raised to a value of 2 . Thus at $750^{\circ} \mathrm{C}$., in $114 \mathrm{hr}$., this material approaches, but apparently does not quite reach, equilibrium. It might be expected that at lower temperatures equilibrium times would become increasingly long, and its attainment would require times beyond those feasible in the laboratory.

There is no evidence that the amount of $\mathrm{NaAlSi}_{3} \mathrm{O}_{8}$ in solid solution has a very considerable effect on the rate at which equilibrium is established.

The following kindly supplied the writers with specimens: Dr A. P. Subramaniam (specimens 2-4 and 18), Prof. Ernst Niggli (specimen 5), Dr N. L. Bowen (specimens 6-7), Prof. Hans Ramberg (specimen 8), and Prof. R. C. Emmons (specimens 17-20). We are indebted to Mr O. Joensuu for spectroscopic analyses. This work was done in conjunction with a research program financed by the Geophysics Branch of the Office of Naval Research.

\section{References}

Cole, W. F., Sörum, H. \& TaYlor, W. H. (1951). Acta Cryst. 4, 20.

Cowley, J. M. (1950a). J. Appl. Phys. 21, 24.

Cowley, J. M. (1950b). Phys. Rev. 77, 669.

Edmunds, I. G. \& Hinde, R. M. (1952). Proc. Phys. Soc. $B, 65,716$.

Emmons, R. C. (1953). Geological Society of America, Memoir 52.

Foster, W. R. (1952). Amer. Min. 37, 758.

GAX, P. (1953). Miner. Mag. 30, 169.

Gax, P. \& TAYlor, W. H. (1953). Acta Cryst. 6, 647.

Goldsmith, J. R. (1952). J. Geol. 60, 288.

Goldsmith, J. R. \& Laves, F. (1951). A. C. A. Meeting, Chicago, October 1951. (Abstract, p. 11.)

Goldsmith, J. R. \& Laves, F. (1954). Geochim. et cosmoch. Acta, 5, 1.

LAves, F. (1952a). J. Geol. 60, 436.

LAvEs, F. (1952b). J. Geol. 60, 549.

Laves, F. \& Goldsmith, J. R. (195la). International Congress of Crystallography, Stockholm, June 1951. (Abstract.)

Laves, F. \& Goldsmith, J. R. (1951b). A. C. A. Meeting, Chicago, October 1951. (Abstract, p. 10.)

LAVES, F. \& GoLdsmith, J. R. (195lc). Mineralogical Society of America Meeting, Detroit, November 1951. (Abstract; also Amer. Min. (1952), 37, 295.)

Laves, F. \& Goldsmith, J. R. (1954). Acta Cryst. 7, 131. Lipson, H. (1950). Progress in Metal Physics, 2, 1.

SöRUM, H. (1951). K. norske vidensk. Selsk. Skr. No. 3. Sörum, H. (1953). Acta Cryst. 6, 413. 